\title{
TOAD POISONING IN THREE DOGS: CASE REPORTS
}

\section{Barbosa CM (1), Medeiros MS (1), Riani Costa CCM (1), Camplesi AC (1), Sakate} M. (1)

(1) Department of Veterinary Clinics, Veterinary Medicine and Animal Husbandry School, São Paulo State University, UNESP, Botucatu, São Paulo State, Brazil.

\begin{abstract}
Toad poisoning is frequent in dogs, but has been infrequently addressed in published case reports and review articles. Dogs can be poisoned when they bite a toad or otherwise ingest the venom. The venom effects manifest soon after the accident, since the toxin is rapidly absorbed by the mucous membrane of the digestive system. Hospital records of three dogs, diagnosed with toad poisoning, were retrospectively reviewed from January 2005 to July 2007. Poisoned dogs may present only local irritation or systemic signs in the gastrointestinal, cardiac and neurological systems. All three cases presented herein had clinical signs of gastrointestinal alterations including vomiting, sialorrhea and diarrhea. Two dogs developed abnormal cardiac rhythm and two exhibited neurological signs. A poisoned animal requires emergency care and symptomatic therapy with intense monitoring of its clinical parameters. Although there have been reports on the low mortality of dogs poisoned by toads, one animal died even after appropriate therapy. The severity of clinical signs and the risk of death must be considered by the veterinarian.
\end{abstract}

KEY WORDS: veterinary emergency, poisoning, toad venom, bufotoxin, Bufo sp., dog.

CONFLICTS OF INTEREST: There is no conflict.

\section{CORRESPONDANCE TO:}

MICHIKO SAKATE, Departamento de Clínica Veterinária, Faculdade de Medicina Veterinária e Zootecnia, UNESP, Distrito de Rubião Jr, s/n, Botucatu, SP, 18.618000, Brasil. Phone: +55 143811 6280. Fax: +55 143811 6067. Email: michikos@fmvz.unesp.br. 


\section{INTRODUCTION}

Toads (order Anura, family Bufonidae, genus Bufo) present a worldwide distribution. In Brazil, many species are found (1-3). Although some are venomous, not all toads produce secretions with sufficient toxicity to cause death in animals (1, 4). In Brazil, the most common extant species are: B. ictericus, B. paracnemis, B. rufus, B. marinus and $B$. shneideri (4). Dogs can be poisoned when they bite a toad or otherwise ingest the venom $(5,6)$.

Although toads cannot inoculate venom, they are considered poisonous animals due to their skin glands, known as parotid glands, which secrete venom of variable toxicity (7). The effects of toad venom manifest soon after the contact, since the toxin is rapidly absorbed by mucous membranes of the digestive system (8).

Substances present in toad venom (Bufo sp.) are divided into two groups, biogenic amines (basic compounds) and steroid derivatives (9). Examples of biogenic amines are adrenalin and noradrenalin - agonists of the sympathetic autonomic nervous system - as well as bufotenine, dihydrobufotenine and bufotionin that present hallucinogenic effects by acting on the central nervous system $(9,10)$. Among steroid derivatives, there are bufodienolide and bufotoxin, whose actions are similar to those of digitalis, inhibiting the sodium-potassium pump in cardiac muscle cells $(9,11)$.

Regarding bufotoxin, clinical findings compatible with poisoning include gastrointestinal, cardiac and neurological problems (12). These signs can be classified into three groups according to symptom severity: mild, moderate or severe. In mild cases, clinical signs consist of oral mucous membrane irritation and sialorrhea. Moderate poisonings present, besides oral mucosa inflammation and sialorrhea, vomiting, depression, ataxia, abnormal cardiac rhythm, fecal and urinary incontinence, and neurological disturbances such as walking in circles. In severe cases, in addition to the aforementioned signs, diarrhea, abdominal pain, unresponsive pupils, seizures, pulmonary edema, cyanosis and death may occur (5, $6,13,14)$. Other neurological signs include unresponsive mydriasis, nystagmus and opisthotonus (12). However, there are reports of other less common clinical signs including excitement, progressive muscular paralysis, blindness and vocalization (4, 15).

Clinical diagnosis may be accomplished through anamnesis, if contact between an affected dog and a toad occurred or if a toad was found in the dog's environment. Due to toad nocturnal habits, poisoning usually occurs at night. In cases of death, necropsy 
can confirm the poisoning if parts of a toad are found in the dog's gastrointestinal tract. Other non-specific findings that can help to detect toad poisoning during necropsy are gastrointestinal inflammatory or hemorrhagic process, lung congestion, edema and hemorrhage caused by cardiac failure (15).

Toad poisoning constitutes a life-threatening emergency. Treatment must be immediately initiated with fluid therapy, symptom management, monitoring of cardiovascular and respiratory parameters, and sometimes analgesia or anesthesia (12).

In the current report, the cardiological parameters of three dogs were monitored during hospitalization while electrocardiographic exams were recorded through a computerized electrocardiographic device (ECGPC®, TEB, Brazil).

\section{CASE 1}

In January 2005, a 3-year-old male Rottweiler bit a toad and two hours later was admitted to the Veterinary Hospital of UNESP, in Botucatu. The dog presented intense salivation, prostration, dyspnea, vomiting, hemorrhagic diarrhea, cardiac arrhythmia and two seizure episodes. Electrocardiography revealed respiratory sinus arrhythmia and ventricular tachycardia (Figure 1). Hematological tests (Table 1) revealed leukocytosis $(35,742 / \mu \mathrm{L})$, neutrophilia $(24,304 / \mu \mathrm{L})$, monocytosis $(2,502 / \mu \mathrm{L})$ and increased total plasma protein (TP) $(10 \mathrm{~g} / \mathrm{dL})$.

Biochemical tests (Table 2) indicated elevated levels of urea (210.8 $\mathrm{mg} / \mathrm{dL}$ ), creatinine $(4.8 \mathrm{mg} / \mathrm{dL})$, alanine aminotransferase (ALT) (99 UI/L), alkaline phosphatase (ALP) (334 UI/L), gamma-glutamyltransferase (GGT) (8.3 UI/L), serum TP $(8.7 \mathrm{~g} / \mathrm{dL})$ with increased globulin $(7.0 \mathrm{~g} / \mathrm{dL})$ and decreased levels of albumin $(1.7$ $\mathrm{g} / \mathrm{dL})$. Potassium levels were normal $(4.5 \mathrm{mEq} / \mathrm{L})$. A symptomatic treatment was conducted based on intravenous (IV) fluid therapy $(\mathrm{NaCl} 0.9 \%)$, oxygen ( $3 \mathrm{~L} / \mathrm{min})$, subcutaneous (SC) metoclopramide $(0.5 \mathrm{mg} / \mathrm{kg}$, every 8 hours), SC ranitidine (2.0 $\mathrm{mg} / \mathrm{kg}$, every 8 hours), SC enrofloxacin $(5.0 \mathrm{mg} / \mathrm{kg}$, every 12 hours), IV metronidazole (15 mg/kg, every 12 hours), IV diazepam $(0.5 \mathrm{mg} / \mathrm{kg})$, IV furosemide $(4.0 \mathrm{mg} / \mathrm{kg})$, and IV bolus of lidocaine $(2.0 \mathrm{mg} / \mathrm{kg})$. On the following day, since there was no cardiac rhythm improvement, lidocaine was associated with oral propranolol $(0.6 \mathrm{mg} / \mathrm{kg})$ every 8 hours. A clinical progress was observed on the fifth day of treatment and all medications were prescribed for home use. Four months later, the animal continued the treatments but no cardiologic problems were found. 


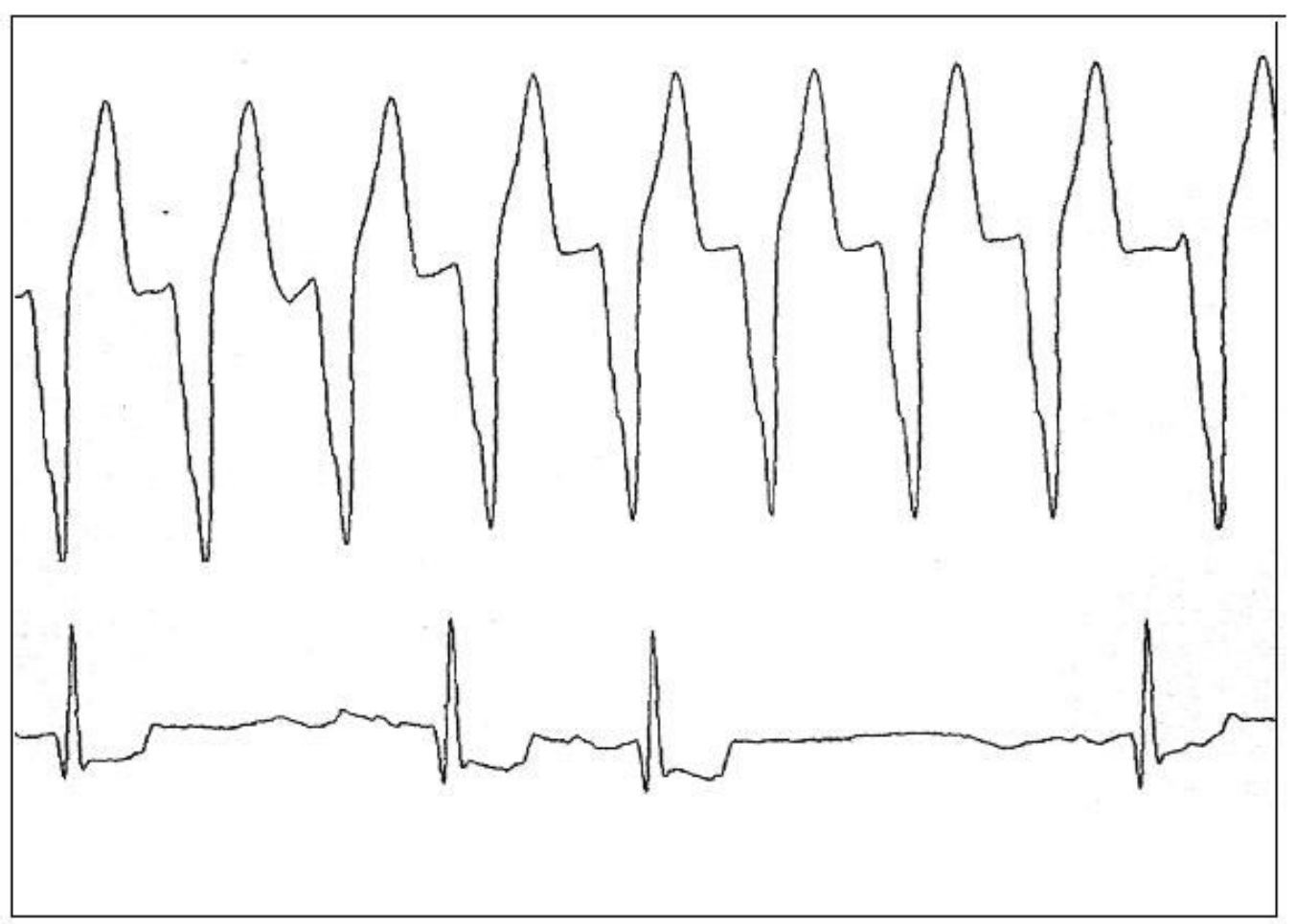

Figure 1. Ventricular tachycardia and respiratory sinus arrhythmia in a male dog poisoned by bufotoxin.

Table 1. Hematological findings in the three dogs poisoned by bufotoxin

\begin{tabular}{lllll} 
& Case 1 & Case 2 & Case 3 & Reference (16) \\
\hline $\mathrm{Ht}(\%)$ & 50 & 51 & 60 & $37-54$ \\
\hline TP $(\mathrm{g} / \mathrm{dL})$ & 10 & 8.6 & 5.4 & $5.4-7.1$ \\
\hline Leukocytes $(/ \mu \mathrm{L})$ & 35,742 & 29,505 & 500 & $6,000-17,000$ \\
\hline Neutrophil $(/ \mu \mathrm{L})$ & 24,304 & 26,555 & - & $3,000-11,500$ \\
\hline Lymphocyte $(/ \mu \mathrm{L})$ & 3,217 & 2,360 & - & $1,000-4,800$ \\
\hline Eosinophil $(/ \mu \mathrm{L})$ & 5,719 & 0 & - & $100-1250$ \\
\hline Monocyte $(/ \mu \mathrm{L})$ & 2,502 & 590 & - & $150-1350$ \\
\hline Platelets $(/ \mu \mathrm{L})$ & 159,075 & 240,000 & 126250 & $160,000-430,000$ \\
\hline
\end{tabular}


Table 2. Biochemical findings of Case 1 dog poisoned by bufotoxin

\begin{tabular}{lll} 
& Case 1 & Reference (16) \\
\hline Urea $(\mathrm{mg} / \mathrm{dL})$ & 210 & $2.5-89$ \\
\hline Creatinine $(\mathrm{mg} / \mathrm{dL})$ & 4.8 & $0.4-1.2$ \\
\hline ALT $(\mathrm{Ul} / \mathrm{L})$ & 99 & $15-58$ \\
\hline ALP $(\mathrm{UI} / \mathrm{L})$ & 334 & $10-73$ \\
\hline GGT $(\mathrm{Ul} / \mathrm{L})$ & 8.3 & $1-5$ \\
\hline TP $(\mathrm{g} / \mathrm{dL})$ & 8.7 & $5.4-7.1$ \\
\hline Globulin $(\mathrm{g} / \mathrm{dL})$ & 7.0 & $2.4-4$ \\
\hline Albumin $(\mathrm{g} / \mathrm{dL})$ & 1.7 & $2.5-3.6$ \\
\hline Potassium $(\mathrm{mEq} / \mathrm{L})$ & 4.5 & $4.2-5.6$ \\
\hline
\end{tabular}

\section{CASE 2}

A 2-year-old female Rottweiler was admitted at the Veterinary Hospital of UNESP, Botucatu, in August 2005, after biting a toad at the previous night. The animal had intense salivation, vomiting, apathy, pasty feces and cardiac arrhythmia. Systolic blood pressure was normal $(140 \mathrm{mmHg})$. Electrocardiography revealed respiratory sinus arrhythmia and ventricular tachycardia. Hematological findings (Table 1) revealed leukocytosis $(29,505 / \mu \mathrm{L})$, neutrophilia $(26,555 / \mu \mathrm{L})$ and increased TP $(8.6$ $\mathrm{g} / \mathrm{dL}$ ). The animal was treated with IV fluid therapy (Ringer solution), SC metoclopramide and ranitidine (every 12 hours), SC enrofloxacin (every 12 hours) and IV infusion of lidocaine (50 $\mu \mathrm{g} / \mathrm{kg} /$ minute). Since there was no cardiac rhythm improvement, lidocaine was substituted by IV amiodarone $(10 \mathrm{mg} / \mathrm{kg})$. The cardiac rhythm returned to normality one day following the treatment with amiodarone. Three days after treatment, blood count revealed normal values and clinical signs disappeared.

\section{CASE 3}

In July 2007, a 1-year-old male Teckel, that had bitten a toad at the previous night, was admitted to the Veterinary Hospital of UNESP, Botucatu. The observed clinical signs were sialorrhea, pasty feces, vomiting, seizure, vocalization, excitement, little 
responsiveness to the environment and mydriasis. Hematological findings (Table 1) included increase in hematocrit (60\%), thrombocytopenia $(126,250 / \mu \mathrm{L})$ and severe leukopenia $(500 / \mu \mathrm{L})$. No alterations were observed in the electrocardiographic exam (Figure 2) and urinalysis. The animal was treated with IV fluid therapy ( $\mathrm{NaCl} 0.9 \%$ ), IV enrofloxacin and metronidazole, IV bolus of diazepam (1.5 mg/kg) and intramuscular (IM) phenobarbital $(4.0 \mathrm{mg} / \mathrm{kg}$, every 8 hours). Despite all care and treatment, the animal died the same day it arrived at the hospital.

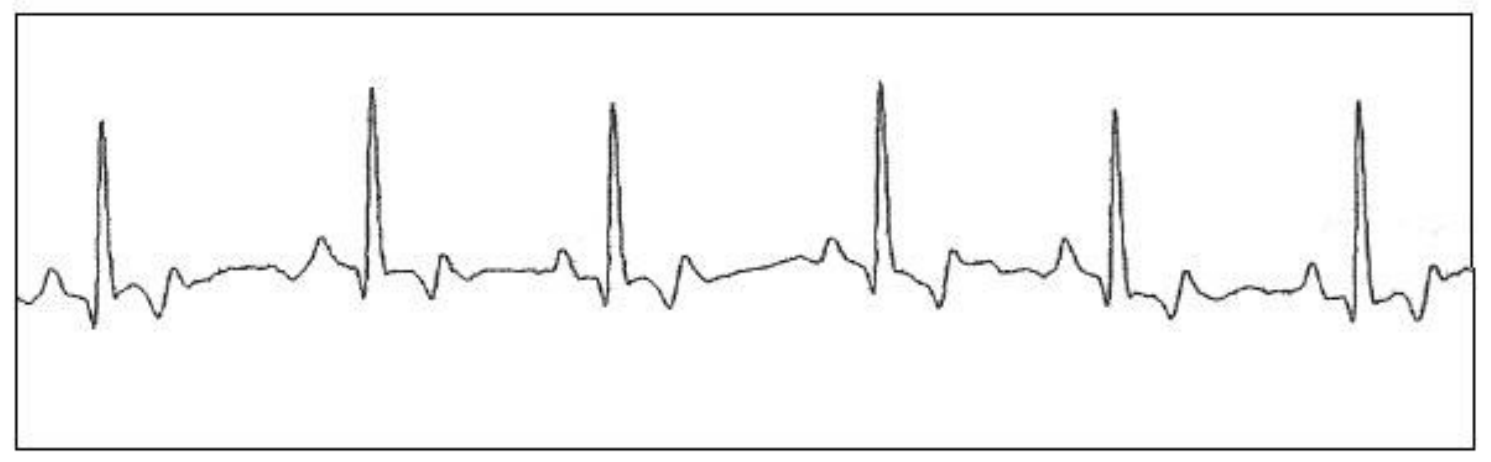

Figure 2. A normal electrocardiographic exam, with sinusal rhythm, from a male dog poisoned by bufotoxin.

\section{DISCUSSION}

Dogs can be poisoned by biting or ingesting the venom of toads (Bufo sp.), which presents variable toxicity. Envenomation effects range from local irritation (oral and gastric mucous membrane) to systemic signs that eventually culminate in the death of the affected dog (1). The most common clinical manifestations are gastrointestinal, cardiac and neurological problems (12). Clinical outcomes vary due to several factors, including toad species, habitat, venom potential and individual sensitivity of victims $(1,5,11)$.

Poisoned animals must immediately receive emergency and symptomatic therapy (12). However, there are numerous divergences concerning treatment for toad poisoning (1).

In the present report, all three bufotoxin-poisoned dogs presented gastrointestinal symptoms such as vomiting, sialorrhea and diarrhea. Part of the venom can be removed with vomiting and sialorrhea, reducing the toxic effects of the venom and "washing" the oral cavity $(6,8)$. It is known that toxin absorption by the oral and gastric mucous membrane is rapid, so elimination of non-absorbed venom of the 
victim's body is important (1). The use of IV sodic pentobarbital (barbituric of short duration), $30 \mathrm{mg} / \mathrm{kg}$, enables the orotracheal intubation, if it is necessary (15). Activated charcoal can be used in the treatment; however, it is more efficient in cases of recent toxin ingestion due to the rapid absorption by the mucous membrane (2).

In the three cases reported, dogs had systemic clinical signs indicating that almost all venom was absorbed by the time of the initial treatment. Therefore, oral or gastric washing, vomiting induction and activated charcoal were not done in those animals. Moreover, dogs of cases 1 and 3 were prostrated, so vomiting induction was contraindicated (16).

The use of atropine to reduce salivation and lung secretions is not recommended since it reduces poison elimination the through saliva (15). Thus, in the current study, atropine was not employed. Antiemetic therapy was utilized in dogs 1 and 2 only in the end of the first day, after all critical care management, in order to stop nausea and persistent vomiting caused by gastric irritation.

In another experimental study carried out by Camplesi (12), with dogs poisoned by toad venom, $100 \%$ of the animals presented neurological signs including mydriasis with no response to light stimulus, nystagmus, depression, stupor, tachypnea, opisthotonus and ataxia. Neurological signs were observed in dogs 1 and 3 that presented seizures, vocalization, excitement and mydriasis.

Electrocardiographic alterations after toad poisoning comprise gradual deterioration of normal patterns with progressive negative ventricular deflections and ventricular rhythm with negative and deep QRS complexes. Eventually, if the affected dog is not treated, a chaotic ventricular rhythm, called ventricular fibrillation, may appear (1). Dogs 1 and 2 presented abnormalities in cardiac rhythm, including arrhythmias of ventricular origin, caused by the action of the toxins bufadienolid and bufotoxin, which is similar to that of digitalis.

In the treatment of arrhythmia in dogs 1 and 2, lidocaine alone was not efficient and the association or substitution for another antiarrhythmic was necessary. This occurred because lidocaine is not effective in cases that develop negative ventricular deflections (1). Beta-blocker agents as antiarrhythmics are indicated by several authors for treatment of ventricular arrhythmias provoked by toad venom, but they can induce serious bradycardia that can lead the dog to death $(1,8,14)$. Propranolol was efficient in association with lidocaine for dog 1 , which recovered the sinus rhythm. In dog 2, the substitution of lidocaine for amiodarone in order to control 
arrhythmia was successful. However, amiodarone is not indicated by Sakate and Oliveira (1), since it was not effective in controlling premature ventricular complexes in an experimental study with dogs poisoned by toad venom $(66 \%$ of the animals treated with this drug died).

Arterial blood pressure increase is a common alteration in dogs poisoned by Bufo sp. and was observed by Camplesi (12) in $90 \%$ of poisoned dogs. This is a consequence of the presence of biogenic amines - like adrenalin, noradrenalin and serotonin - in the venom composition, besides bufotenine. Such substances are powerful vasoconstrictors that improve vascular peripheral resistance, increasing blood pressure (6). Dog 2 presented normal systolic blood pressure.

In previous works, dogs experimentally poisoned by toad venom presented an increase in hematocrit as well as neutropenia and lymphopenia $(14,17)$. In the current report, dog 3 presented an increase in hematocrit (60\%) and severe leukopenia. In general, toad venom causes inflammatory reactions in the digestive system (12). Similarly, in our observation, the blood count of dogs 1 and 2 suggested inflammation (leukocytosis with neutrophilia). Antibiotic therapy was employed in order to avoid risks of septic complications in animals with clinical signs of serious intoxication.

In a previous study on experimental poisoning in dogs, glucose, urea and calcium were augmented while sodium, phosphorus and TP dropped; hypoalbuminemia and no alteration in ALT and ALP enzymes were also reported (14). In another experiment with dogs, toad venom had not caused kidney injury, so it was considered not toxic for the kidneys (17). In the present report, dog 1 showed elevated levels of urea, creatinine, ALT, ALP, GGT, TP, as well as hyperglobulinemia and hypoalbuminemia. Azotemia (increased urea and creatinine) can be secondary to dehydration or a result of renal failure. The venom metabolism is hepatic, so that elevated ALT suggests hepatic injury while increase of ALP and GGT indicate cholestasis $(18,19)$.

Hyperkalemia is frequent in dogs and humans poisoned by toads, but hypokalemia has also been reported (20). Dog 1 had normal potassium level.

Hyperkalemia, hypercalcemia and reduced plasma sodium levels are reasonable in poisoning by bufotoxin, since it inhibits the sodium-potassium pump. This blockage leads to an accumulation of extracellular potassium, increasing intracellular sodium and stimulating the exchange of sodium, potassium and calcium, consequently 
increasing calcium concentration in myocardium cells $(6,11,14)$. Hyperkalemia can be treated with glucose, insulin or bicarbonate (2).

Studies have reported low mortality rates of dogs poisoned by toads (Bufo sp.) after adequate treatment $(1,6,14,21)$. Toad envenoming in dogs may cause local and systemic alterations and also death by cardiac ventricular fibrillation (15). Anesthesia with pentobarbital sodium increases the lifespan of dogs poisoned by toad venom (14).

According to Eugib (11), the dog size is important since the poisoning is more severe in smaller animals. Dog 3 was the smallest and youngest among the studied animals and died even with the treatment. The clinical severity, the time of exposure to the venom, and the amount and toxicity of the venom interfere in the treatment and prognosis.

The current report presents the significance of envenomations by bufotoxin in dogs, which have different clinical presentations and signs, demonstrating the importance of an emergency and symptomatic therapy with intense monitoring of the animal.

\section{REFERENCES}

1. Sakate M, Lucas de Oliveira PC. Use of lidocaine, propanolol, amiodarone, and verapamil in toad envenoming (genus Bufo) in dogs. J Venom Anim Toxins. 2001;7(2):240-59.

2. Moyano Salvago MR, Molina Lopez AM, Lora Benítez AJ, Rufino Moya PJ, Fernández-Palacios O'Connor R, Camacho Sillero LN. Intoxicación aguda en perro por toxinas de sapo (Bufo bufo). Rev Electrón Vet; 2009;10(4):1-5.

3. Soone L, Rozza DB, Wolffenbuttel AN, Meirelles AEWB, Pedroso PMO, Oliveira EC, et al. Intoxicação por veneno de sapo em um canino. Cienc Rural. 2008;38(6):1787-9.

4. Sakate M. Terapêutica das intoxicações. In: Andrade SF, editor. Manual de terapêutica veterinária. São Paulo: Roca; 2002. p. 523-55.

5. Knowles RP. Toad poisoning in dogs. J Am Vet Med Assoc. 1968;153:1202.

6. McFarland PJ. Toad toxicity. Aust Vet Pract. 1999;29(3):98-103.

7. Chen KK, Chen AL. Notes on the poisonous secretions of twelve species of toads. J Pharmacol Exp Ther. 1933;47:281-93.

8. MacDonald B. Terrier toad toxicity syndrome. Aust Vet Pract. 1990;20(2):118.

9. Zelnik R. A natureza química do veneno de sapo. Cienc Cult. 1965;17:10-4. 
10. Chen KK, Koraríková A. Pharmacology and toxicology of toad venom. J Pharm Sci. 1967;56(12):1535-41.

11. Eugib PA. Bufo especies toxicosis: big toad, big problem. Vet Med. 2001;96(8):594-9.

12. Camplesi AC. Avaliações clínicas e laboratoriais da intoxicação experimental por veneno de sapo em cães [master's thesis]. Botucatu: Universidade Estadual Paulista, Faculdade de Medicina Veterinária e Zootecnia; 2006. 103 p.

13. Otani A, Palumbo N, Read G. Pharmacodynamics and treatment of mammals poisoned by Bufo marinus toxin. Am J Vet Res. 1969;30(10):1865-72.

14. Palumbo NE, Perry SF. Toad poisoning. In: Kirk RW, editor. Current veterinary therapy: small animal practice. $8^{\text {th }}$ ed. Philadelphia: W.B. Saunders; 1983. p. 160-2.

15. Sakate M, Lucas de Oliveira PC. Toad envenoming in dogs: effects and treatment. J Venom Anim Toxins. 2000;6(1):52-62.

16. Meyer DJ, Harvey JW. Veterinary laboratory medicine: interpretation and diagnosis. $3^{\text {rd }}$ ed. Philadelphia: W.B. Saunders; 1998. p. 307-9.

17. Simão NMB. Intoxicação experimental por veneno de sapo em cães anestesiados: estudos clínico e laboratorial [master's thesis]. Botucatu: Universidade Estadual Paulista, Faculdade de Medicina Veterinária e Zootecnia; 2007. 94 p.

18. Kerr MG. Exames laboratoriais em medicina veterinária: bioquímica clínica e hematologia. $2^{\text {nd }}$ ed. São Paulo: Roca; 2003. 436 p.

19. Kaneko JJ, Harvey JW, Bruss ML. Clinical biochemistry of domestic animals. $5^{\text {th }}$ ed. San Diego: Academic Press; 1997. 932 p.

20. Chi HT, Hung DZ, Hu WH, Yang DY. Prognostic implications of hyperkalemia in toad toxin intoxication. Human Exp Toxicol. 1998;17(6):343-6.

21. Palumbo NE, Perri S, Read G. Experimental induction and treatment of toad poisoning in the dog. J Am Vet Med Assoc. 1975;167(11):1000-5. 